\title{
TINO CASAL Y LA MODERNIZACIÓN DEL POP ESPAÑOL EN LOS AÑOS OCHENTA
}

\section{TINO CASAL AND THE MODERNIZATION OF SPANISH POPULAR MUSIC IN THE EIGHTIES}

\author{
Sara Arenillas Meléndez \\ Universidad de Oviedo \\ sara.arenillas@gmail.com \\ ORCID ID: https://orcid.org/0000-0002-4613-3816 \\ Diana Díaz González \\ Universidad de León \\ ddiag@unileon.es \\ ORCID ID: https://orcid.org/0000-0002-1146-2935
}

\section{Resumen}

Tino Casal (1950-1991) es una referencia de la música popular urbana española de la década de 1980 y uno de los que mejor adaptó la modernidad posmoderna de la new wave al contexto español. Casal articuló el discurso de la new wave a través de los new romantics, que recogían elementos del glam como el artificio o la androginia. En su trabajo, Casal combinó, siguiendo a sus homólogos extranjeros, la artificialidad y la auténtica inautenticidad del synth pop, con la práctica del pastiche y el uso consciente del kitsch. Siguiendo la cronología de sus discos, en este artículo analizamos cómo Casal construyó este discurso a través del análisis de canciones clave como "Embrujada", "Oro negro", "African chic" o su versión de "Life on Mars?".

\section{Palabras clave}

Tino Casal, Nuevos Románticos, Movida, new wave, autenticidad inauténtica, posmodernidad, synth pop, kitsch, músicas populares urbanas.

\section{INTRODUCCIÓN}

La propuesta artística de José Celestino Casal Álvarez (Tudela Veguín, Asturias, 1950-Madrid, 1991), conocido como Tino Casal, no ha sido aún estudiada en profundidad dentro de los estudios de musicología popular llevados a cabo

\begin{abstract}
Tino Casal (1950-1991) is an icon for Spanish popular music of the 1980s. Casal adapted efficiently new wave's postmodern modernity to the Spanish context. He articulated the discourse of the new wave through new romantics, who inherited features of glam such as artifice or androgyny. Following his foreign counterparts, Casal combined in his work synth pop's artificiality and authentic inauthenticity, with pastiche and kitsch. In this research, we have analyzed Casal's work through songs like "Embrujada", "Oro negro", "African chic" or his version of "Life on Mars?". For the structure, we have followed the chronological timeline of his recordings to appreciate Casal's evolution throughout the eighties.
\end{abstract}

\section{Key words}

Tino Casal, new romantics, Movida, new wave, authentic inauthenticity, postmodernity, synth pop, kitsch, Spanish popular music.

en España. ${ }^{1}$ Actualmente existe un interés renovado en recupe-

\footnotetext{
${ }^{1}$ Esta investigación se enmarca en el proyecto Músicas en conflicto en España y Latinoamérica: entre la hegemonía y la transgresión (siglos XX y XXI) (HAR2015-64285-C2-1-P).
} 
rar su obra, en particular desde la escena musical asturiana. ${ }^{2}$ Por eso consideramos importante estudiar su figura desde un punto de vista académico, que complete las aproximaciones periodísticas que se han realizado hasta el momento.

Casal debutó en 1964 como vocalista del grupo Los Zafiros Negros, colaborando luego con Los Archiduques hasta 1970 . $^{3}$ Después de este periodo llegaron unos años que el periodista Gerardo Quintana denomina “de transición"; ${ }^{4}$ Casal pasó a formar parte de la compañía Fonogram, quienes le lanzaron como cantante melódico en festivales de "canción ligera". ${ }^{5} \mathrm{Ca}$ sal no estaba satisfecho con el perfil de "cantante folklórico/ melódico" que tenía entonces ${ }^{6}$ y empezó a plantearse un cambio de rumbo que le ofreciera la oportunidad de poner en práctica un discurso más acorde con sus influencias (David Bowie y Roxy Music, entre otros). ${ }^{7}$ En los años ochenta Casal dio un giro a su carrera con el lanzamiento de su primer álbum en solitario, Neocasal $;{ }^{8}$ salió a la venta en 1981, junto a singles como el exitoso "Champú de huevo". El disco presentaba el novedoso y "moderno" universo por el que más tarde se ha reconocido al artista. Neocasal y el resto de los álbumes de Casal fueron producidos por Julián Ruiz, con el que afirmaba trabajar "de maravilla”. ${ }^{9}$ En 1983 Casal publicó Etiqueta Negra y alcanzó amplia difusión gracias a temas contenidos en él como "Embrujada". Casal lanzó varios trabajos más, Hielo Rojo (1984), Lágrimas de Cocodrilo (1987) - que incluía la famosa versión del tema "Eloise" - , y 1990 Histeria (1989), hasta la fecha de su muerte en 1991.

Casal se distinguió en los ochenta por adaptar el discurso de los new romantics (Nuevos Románticos), corriente que estaba en auge en el Reino Unido en aquel momento y que se englo-

\footnotetext{
${ }^{2}$ Por ejemplo, el artista asturiano Rodrigo Cuevas publicó hace dos años, como homenaje, un single con versiones de los temas de Tino Casal "Embrujada y Pánico en el Edén" (Aris Musica, 2017).

${ }^{3}$ Sergio Guillén Barrantes y Andrés Puente Gómez, Glam rock: sexo, purpurina y lápiz de labios (Lleida: Milenio, 2010), "Spain is different", pp. 137-138; y Salvador Domínguez, Bienvenido Mr. Rock: los primeros grupos hispanos, 1957-1975 (Madrid: Sociedad General de Autores y Editores, 2002).

${ }^{4}$ Gerardo Quintana, Tino Casal: Más allá del embrujo (Madrid: T\&B Editores, 2007)

${ }^{5}$ Casal llegó incluso a ser finalista en el Festival de Benidorm de 1978 con el tema "Emborráchate"; véase Guillén y Puente, "Spain is different", p. 138.

${ }^{6}$ Miguel Ángel Arenas, “Tino Casal: La isla del Glamour”, Rock Espezial, 23 (julio de 1983), pp. 46-47.

7 José Miguel Jauregui, "Las diez mejores de...Tino Casal”, El Gran Musical, 234 (Madrid, agosto de 1983), p. 15.

${ }^{8}$ Diego A. Manrique, "Tino Casal: Peluquería musical”, Rock Espezial, 3 (noviembre de 1981), p. 59. El disco fue lanzado dentro del sello EMI, gracias a la intervención de Rafael Gil, director por entonces de la compañía.

9 Isabel Vallina, "El discreto encanto del productor", El Gran Musical, 229 (Madrid, marzo de 1983), pp. 17-19; y Alberto Vila, "Tino Casal. Tigre Bengalî”, El Gran Musical, 240 (Madrid, febrero de 1984), p.
} 38. baba dentro de la new wave (Nueva Ola). La propuesta de Casal resultaba novedosa por estar al día respecto al panorama del pop y el rock anglosajón, conectando con lo que estaban haciendo los artistas de la Movida, considerada la new wave o Nueva Ola española. ${ }^{10}$ Como veremos, Casal adaptaba a través de los new romantics de forma eficaz el discurso de modernidad que, como desarrollaremos, según Theo Cateforis, permeaba la new wave. ${ }^{11}$ De este modo, aunque Casal pertenece a una generación anterior a la de la mayoría de los integrantes de la Movida, autores como José Manuel Lechado han considerado que "desde el punto de vista de la Movida..., Tino Casal fue al género masculino lo que Alaska al femenino". ${ }^{12}$

En el presente artículo hemos analizado cómo Tino Casal articuló el discurso de modernidad que caracterizaba a la new wave y los Nuevos Románticos, y que en España se ha relacionado con la Movida. Para ello, articulamos la aplicación de conceptos surgidos desde el ámbito de los estudios culturales fundamentalmente la "auténtica inautenticidad" que postula Lawence Grossberg - ${ }^{13}$ y sobre músicas populares urbanas especialmente el trabajo de Theo Cateforis sobre la new wa$v e-,{ }^{14}$ con estrategias más cercanas a la musicología tradicional, como el análisis de componentes musicales de una selección de ejemplos musicales representativos, incluyendo transcripciones rítmicas y melódicas. Para organizar los contenidos de este trabajo hemos considerado seguir un orden cronológico basado en la discografía de Casal, de manera que la estructura y el desarrollo del discurso, con base académica y la adición de fuentes hemerográficas de la época, permiten apreciar la evolución musical y artística de Tino Casal de manera amplia. Asimismo, nos hemos centrado en la producción de Casal de la década de 1980, por considerar que es la más representativa y la que logró sus mayores éxitos.

${ }^{10}$ William J. Nichols and H. Rosi Song, Toward a Cultural Archive of La Movida: Back to the Future (Madison, WI: Fairleigh Dickinson University Press, 2014) y Héctor Fouce, El futuro ya está aquí: música pop y cambio cultural (Madrid: Velecío Editores, 2006).

${ }^{11}$ Véase Theo Cateforis, Are We Not New Wave? Modern Pop at the Turn of the 1980s (Ann Arbor: University of Michigan Press, 2011).

12 José Manuel Lechado García, La movida: una crónica de los 80 (Madrid: Algaba, 2005), p. 64. Cabe señalar que Casal se instaló a mediados de los setenta en Madrid, donde comenzó a frecuentar el entorno de los pintores Juan Carreño y Enrique Naya, apodados "Las Costus" y a quienes dedicó su disco Histeria; véase Santiago Erice, "Tino Casal. Observándose en el espejo", Popular, 1/200 (marzo de 1990), pp. 8-9. También entabló amistad con Fabio de Miguel (Fabio McNamara), con el que vivió durante un tiempo; véase Mario Vaquerizo, Fabiografía: Fabio McNamara (Barcelona: Espasa, 2014), pp. 53-67.

${ }^{13}$ Lawrence Grossberg, We Gotta Get Out of This Place: Popular Conservatism and Postmodern Culture (Londres y Nueva York: Routledge, 1992), "Rock, posmodernity and authenticity", pp. 201-39. 1980 s. 


\section{NEOCASAL: LA NOSTALGIA DEL GLAM}

El momento en el que, como hemos señalado, Tino Casal se replantea su carrera en torno a 1980 coincide con el surgimiento en Londres del movimiento de los new romantics. Casal llevaba años viajando en compañía de su novia Pepa Ojanguren a Londres, donde ambos se empapaban de las propuestas estéticas y musicales del momento. ${ }^{15}$ Él era conocedor del discurso de bandas que surgieron a principios de los ochenta dentro del movimiento new romantic como Visage, Ultravox, The Human League, Soft Cell, Culture Club o Japan.

A nivel musical, los Nuevos Románticos facturaban un pop con sintetizadores (techno o synth pop) que contenía ritmos bailables y melodías pegadizas. No obstante, según autores como Cateforis, los Nuevos Románticos hacían uso de las connotaciones de experimentación y modernidad que implicaba el uso de tecnología electrónica ${ }^{16}$ A nivel visual, los new romantics creaban una estética que recogía la esencia romántica de la huida y la evasión hacia un mundo de ficción, futuro o pasado; por ejemplo, Marc Almond de Soft Cell aparecía caracterizado de romano en el videoclip de Tainted Love. Los Nuevos Románticos formaban parte de la new wave y eran la facción de ella más influenciada por el glam.${ }^{17}$ En España, la recepción del glam en los setenta fue minoritaria, siendo en los ochenta cuando éste pudo adaptarse, fusionado con las corrientes del momento. ${ }^{18}$ En este contexto es en el que se explica que Casal combinara en su disco debut, Neocasal, el glam rock de los setenta con los new romantics.

El glam era una corriente del rock que se caracterizaba por el énfasis en la imagen y la performance, así como por la ambigüedad de género..$^{9}$ Los new romantics habían nacido, en cierto modo, a raíz del discurso que David Bowie había creado

${ }^{15}$ Según el crítico y presentador Rico Roces y el actor Pepe Rubio, en Quintana, Tino Casal: Más allá del embrujo, pp. 62 y 65: "fue Pepa la que le dijo a Tino todo lo que se estaba cociendo por aquel entonces en Londres: la moda, la música (Roxy Music - con Bryan Ferry y Brian Eno-, T. Rex, Marc Bolan y, sobre todo, el rey, que era David Bowie) (...). Pepa era la más moderna de Oviedo y era seguidora de David Bowie y del glam, (...)".

16 Theo Cateforis, "Roll over Guitar Heroes, Synthesizers Are Here....", en Are We Not New Wave? Modern Pop at the Turn of the 1980s (Ann Arbor, MI: University of Michigan Press, 2011), pp. 151-81.

17 Dave Rimmer, Like Punk Never Happened: Culture Club and the New Pop (Londres: Faber and Faber, 2011), pp. 28-29.

${ }_{18}$ Sara Arenillas Meléndez, "El glam en España y su articulación de las identidades de género", en Musicología en el siglo XXI: Nuevos retos, Nuevos enfoques, ed. Begoña Lolo y Adela Presas (Madrid: Sociedad Española de Musicología, 2018), pp. 2087-2107.

19 Philip Auslander, Performing Glam Rock: Gender and Theatricality in Popular Music (Ann Arbor: University of Michigan Press, 2006). Véase también Andrew Branch, "All the young dudes: educational capital, masculinity and the uses of popular music", Popular Music, 31/1 (2012), pp. 2544; Van M. Cagle, Reconstructing Pop/Subculture: Art, Rock and Andy Warhol (Thousand Oaks, CA: Sage Publications, 1995); y Henry Johnson e Ian Chapman, eds., Global Glam and Popular Music. Style and Spectacle from the 1970s to the 2000s (Nueva York: Routledge, 2016). de nostalgia y futurismo..$^{20}$ Bowie había sido uno de los principales representantes del glam rock en los setenta; los Nuevos Románticos recogieron el glam a través de él y lo mezclaron con el carácter moderno que rodeaba a la new wave. Tino Casal, al igual que otros como Fabio McNamara, se sentía atraído por artes visuales como la pintura, el diseño o la decoración. Casal diseñó portadas para sus discos (ej.: Neocasal), y los de otros como Azul y Negro — La edad de los colores (Mercury, 1981) , y decoraba su propia casa y algunos locales, según informaba la prensa de su época. ${ }^{21}$ Por ello, la inclinación a lo visual del glam, que los new romantics habían recogido, encajaba perfectamente con los intereses de Casal.

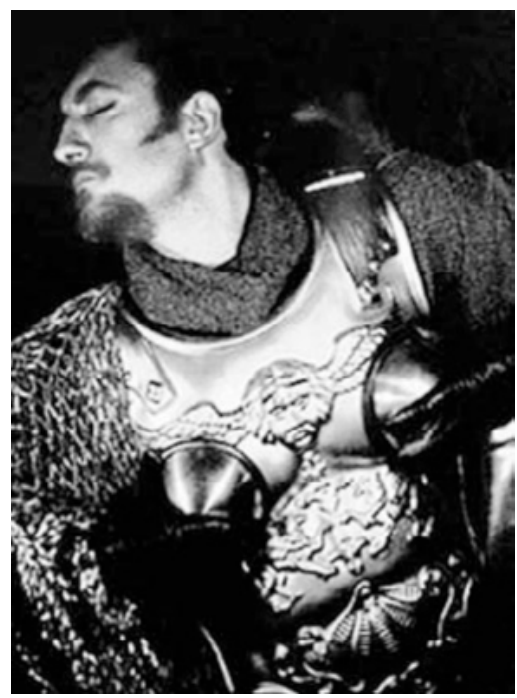

Figura 1. Tino Casal con armadura "romana", en la línea del estilismo y la ambigüedad de género de los new romantics.

En términos de género, los Nuevos Románticos presentaban, como sigue el glam, una imagen andrógina. Al igual que los new romantics, Casal hacía uso de elementos culturalmente asociados con la mujer, como el maquillaje, pero los combinaba con otros que denotaban virilidad, como la barba o las armaduras; véase Figura 1. Igualmente, Casal era consciente de que al centrarse de forma manifiesta en la parte estética estaba haciendo uso de una estrategia que se percibía como femenina y comprendía los riesgos que implicaba el llevarla a cabo. Así, cuando Patricia Godes le preguntaba si le hubiera gustado ser mujer,

\footnotetext{
${ }^{20}$ Prueba de ello es que los afines a la corriente de los new romantics dedicaban la noche de los martes a homenajear a Bowie en el Billy's; véase Dave Rimmer, New Romantics: The Look (Londres: Omnibus Press, 2003), p. 18.

${ }^{21}$ Véanse los artículos anónimos, "Casal: póker para un ganador", El Gran Musical, 233 (Madrid, julio de 1983), p. 33; y "Tino Casal canta las 40: 'Soy bastante mejor de lo que esperaba'", El Gran Musical, 315 (Madrid, abril de 1990), pp. 18-20.
} 
Casal contestaba que "a veces sî”, y explicaba: "me podría permitir [estéticamente] ciertos lujos que como hombre no puedo". ${ }^{22}$ La utilización de estos elementos característicos del glam que los new romantics habían absorbido hizo que Casal fuera percibido como uno de los que más visiblemente mantuvo una "actitud típicamente glam" en España, ${ }^{23}$ "un esteta de la hipérbole, (...). El último rey del glam" ${ }^{24}$

Musicalmente, gran parte del glam británico - lo que Branch define como "rock'n'roll glam"- era un revival del rock clásico de los cincuenta, que articulaban como pop, es decir, entendiendo el rock más como producto comercial, que como arte para minorías. ${ }^{25}$ Los Nuevos Románticos formaban parte de la new wave: esta reflejaba el ascenso de una nueva sensibilidad musical posmoderna. Sin embargo, Cateforis puntualiza que la new wave era etiquetada y reconocida como un movimiento musical "moderno", no "posmoderno". ${ }^{26}$ El elemento sonoro fundamental a través del que la new wave connotaba esta modernidad era el uso de la electrónica y, especialmente, del sintetizador. Los new romantics son un ejemplo de ello, ya que, como se ha apuntado, facturaban un pop hecho con sintetizadores.

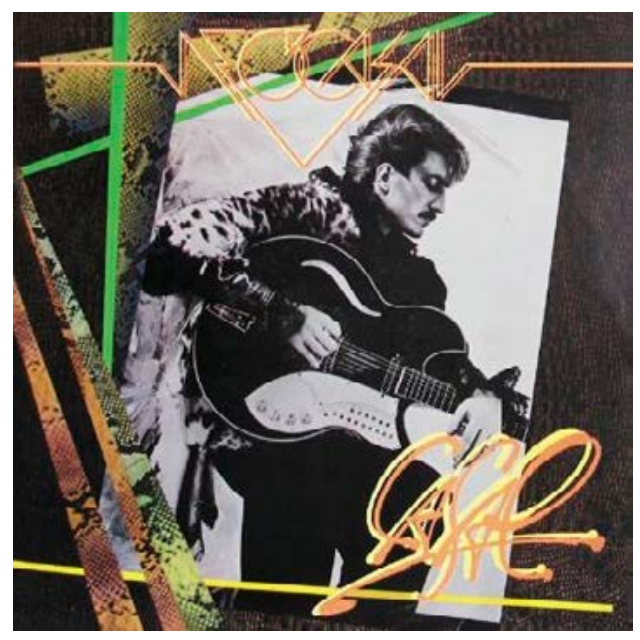

Figura 2. Portada de Neocasal, en la que Casal aparece con una guitarra-órgano Godwin.

En Neocasal, Casal armoniza la inclinación a la electrónica de la new wave y los new romantics con el revival del rock clásico

${ }^{22}$ Patricia Godes, "Casal: Locura o histeria", Rockdelux, 63 (abril de 1990), p. 35.

${ }^{23}$ Guillén y Puente, "Spain is different", p. 138.

${ }^{24}$ Anónimo, "Tino Casal: El último rey del Glam...", Rockdelux, 80 (Barcelona noviembre de 1991), p. 21.

${ }^{25}$ Andrew Branch, "All the young dudes: educational capital, masculinity and the uses of popular Music", Popular Music, 31/1 (2012), pp. 25-44, especialmente 28-29.

${ }^{26}$ Cateforis, "Roll over Guitar Heroes, Synthesizers Are Here....", pp. 3 y 5. que definía a parte del glam. Esto se puede entrever en la portada, en donde Casal, que fundamentalmente era conocido como cantante, aparece con una guitarra, instrumento considerado la quintaesencia del rock. Sin embargo, esta incorporaba también un sintetizador, era una guitarra-órgano Godwin, instrumento que personificaba la nueva modernidad; véase Figura 2.

Neocasal es uno de los pocos discos de Casal en el que la guitarra eléctrica tiene peso en varias canciones; de hecho, hay varios temas en los que podría considerarse que la guitarra realiza riffs, por ejemplo, en "Billy Boy". Asimismo, la alusión a la tecnología puede apreciarse en "Goodnight Hollywood", donde Casal filtra su voz en algunas frases para dar la sensación de robotización, o en "Stupid Boy", donde añade un solo de "ruidos" de sintetizador de medio minuto, a modo de coda. A menudo, los new romantics veían en Japón el símbolo perfecto de su fusión entre modernidad futurista y sofisticación estética; realizan constantes referencias al país nipón, como la banda Japan en su "Life in Tokyo", o Alphaville en su hit "Big in Japan". Casal también hizo uso de este imaginario en el primer corte de $\mathrm{NeO}$ casal, "Tokyo", en el que utiliza el sintetizador para añadir sonidos que parecen procedentes de una computadora. Igualmente, son evidentes las alusiones de Casal a temas de referencia del movimiento new romantic como "Vienna" de Ultravox en “Aquí en Viena", o "Dancing with myself" del grupo de Billy Idol, Generation X, en "Billy Boy". Así pues, tal y como expresa su portada, el uso del sintetizador y de la guitarra se hayan equilibrados en Neocasal.

Neocasal contenía además una adaptación del tema característico de la etapa glam de David Bowie, "Life on Mars?", como homenaje a este artista que había sido fundamental tanto para el glam como para los new romantics. ${ }^{27}$ Casal señalaba: "Bowie para mí siempre supuso todo... [su versión de "Life on Mars?"] contiene la fórmula que él utilizó en el setenta y tantos, pero con instrumentación de ahora y nuevos matices, si te fijas en la segunda parte recuerda incluso a "Ashes to ashes"”. ${ }^{28}$ Lo más destacado del "Life on Mars?" de Bowie era el protagonismo de la elaborada parte de piano, que contenía una rica armonía con ingeniosos cromatismos, y la adición de arreglos de cuerda frotada que potenciaban los clímax y que tenían un sentido de parodia camp. ${ }^{29}$ Tino Casal mantenía la estructura armónica y la línea vocal, que por sus saltos y ornamentos favorecía su lucimiento como cantante, pero realizaba varios cambios en la textura que resultaban clave: su versión incorporaba el sintetizador vintage Prophet 10 , un teclado electromecánico clavinet, y el analizador y sintetizador de voz Vocoder (Todo Casal, EMI, 2011). Con estos instrumentos cambiaba los pasajes de cuerda frotada de la original por arreglos orquestales sintetizados. Ade-

\footnotetext{
${ }^{27}$ Podemos encontrar también referencias a David Bowie en el tema "Billy boy" de Neocasal, donde cita el personaje Ziggy Stardust creado por Bowie en los setenta.

28 Joan Singla, "Neo-realismo romántico", Popular 1/102 (Barcelona, diciembre de 1981), p. 71.

${ }_{29}$ David Buckley, Strange Fascination. David Bowie: The Definitive Story (Londres: Virgin Books, 1999), p. 116.
} 
más, atribuía un menor peso al piano al bajarlo de volumen en la mezcla y añadir un nuevo instrumento que realizaba parte de los solos: el saxofón. Este instrumento había sido clave en la propuesta de bandas glam, como Roxy Music, y new romantic, como Ultravox, que fueron también referencia para Casal. ${ }^{30}$ De esta forma Casal mantuvo la estructura armónica en su versión de "Life on Mars?”, pero modificó la textura del tema. La adición de la electrónica a través de ritmos y sonidos hechos por el sintetizador era sin duda lo más importante, ya que era lo que realmente "modernizaba" la pieza y la actualizaba con la new wave y los new romantics. En la actuación que Casal realizó en televisión para el programa Aplauso en 1981, se ponía énfasis visual en el músico que tocaba el sintetizador, que iba vestido de manera futurista con un traje de raso color champán; véase Figura $3 .^{31}$

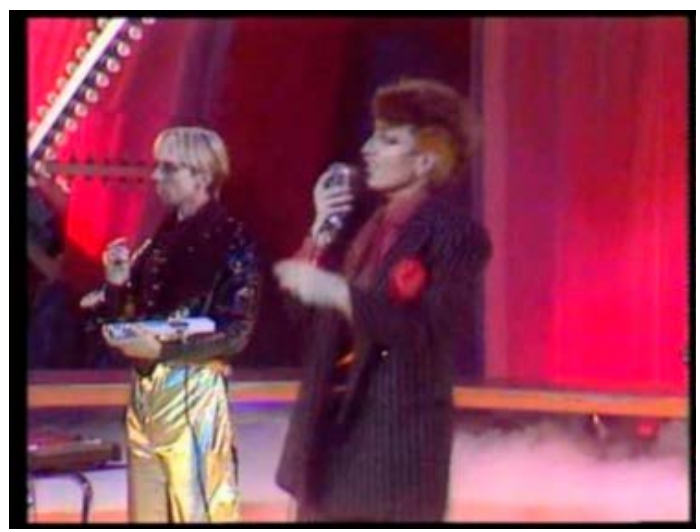

Figura 3. Casal junto al extra que tocaba el sintetizador en su interpretación de "Life on Mars?" en Aplauso, en 1981.
Además, Casal añadió elementos en su versión que son importantes para comprender por qué la comparaba con "Ashes to Ashes", un tema de Bowie incluido en el álbum Scary Monsters, producido por Tony Visconti y lanzado en 1980. Para la grabación de su videoclip, Bowie fue al club de Londres que frecuentaban los new romantics, el Blitz, para incluirlos como extras en el mismo. "Ashes to ashes" compartía con "Life on Mars?" las alusiones al espacio exterior, que estaban presentes también en el tema "Space Oddity". "Ashes to ashes" presentaba el carácter distópico de "Space Oddity" e incluso mencionaba el personaje del astronauta Mayor Tom aparecido en esta. Sin embargo, al contrario que "Life on Mars?" y "Space Oddity", "Ashes to Ashes" sí utilizaba el "moderno" sintetizador, lo cual encajaba con la estética de los new romantics. Además, Bowie aparecía en el videoclip doblemente como astronauta "del futuro" y como romántico y "decimonónico" Pierrot. Esta caracterización encajaba perfectamente con la combinación de futurismo distópico y romanticismo "anticuado" de los Nuevos Románticos. Como señala Dave Rimmer, "el payaso [Pierrot], el astronauta y el interno en un manicomio [que aparecían en el video de "Ashes to Ashes"] son imágenes tomadas del pasado de Bowie.... En esto, más que en nada, los Nuevos Románticos eran claramente su legado". ${ }^{33}$ De este modo, "Ashes to ashes" es probablemente el tema más new romantic de Bowie.

Casal conectaba su versión de "Life on Mars?" con "Ashes to Ashes" de dos formas: incluyendo varios extras en su actuación en Aplauso que iban vestidos como los new romantics del video de Bowie (véase Figura 4), y añadiendo con el sintetizador un ritmo bailable similar al de "Ashes to ashes"; véase Ejemplo 1. El baile era un elemento definitorio de la producción de Casal que encajaba, además, con la new wave y los new romantics; como señala Cateforis, el estilo de la new wave estaba

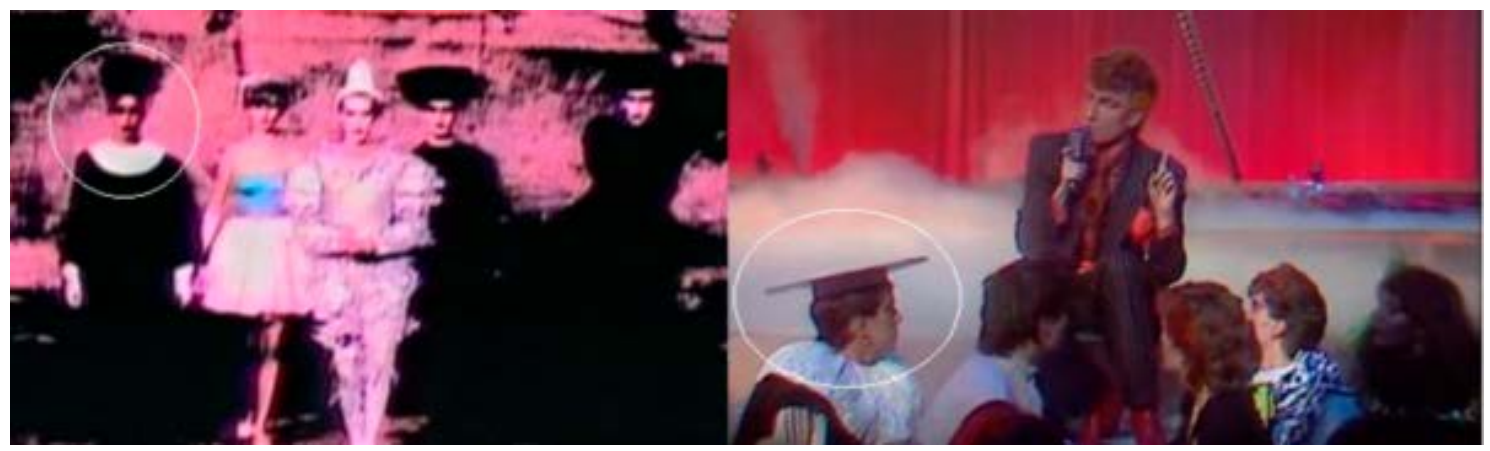

Figura 4. Fotogramas del videoclip de "Ashes to Ashes" de Bowie y de Casal interpretando "Life on Mars?" en Aplauso, con los Nuevos Románticos (rodeados) como extras.

\footnotetext{
${ }^{30}$ Puede observarse el uso de este instrumento en los temas "Hiroshima mon amor" de Ultravox e "If there is something" de Roxy Music; ambos contienen destacados solos de saxofón.

${ }^{31}$ La actuación de Casal en Aplauso está disponible en Youtube <https://www.youtube.com/watch?v=A-3k_ONQttU>, consultado el 4 de abril de 2018 .
}

${ }^{32}$ Victoria Broackes, "Putting out fire with gasoline: desining David Bowie", en David Bowie is (Londres:V\&A Publishing, 2013), pp. 116153.

${ }^{33}$ Rimmer, New Romantics: The Look, p. 18: "But clown, astronaut and asylum inmate are also all images from Bowie's past.... In this, more than anything, the New Romantics were clearly his legacy." 
impregnado del discurso del baile. ${ }^{34}$ El sintetizador entra en el "Life on Mars?" de Casal en la segunda estrofa, a la vez que la percusión en la original, y realiza una síncopa que subraya el carácter bailable del tema. Estas síncopas podrían recordar a las del motivo principal del sintetizador en "Ashes to Ashes", ya que acentúan también la segunda parte del segundo tiempo, y quizá por ello Casal afirmaba que este tema y su versión de "Life on Mars?" se parecían; véase Ejemplo 1.

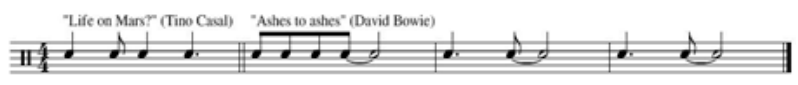

Ejemplo 1. El ritmo de sintetizador de la versión de "Life on Mars?" de Casal (primer compás) y del tema "Ashes to Ashes" de Bowie.

Así pues, Casal incluía en "Life on Mars?" elementos visuales y sonoros que lo adaptaban a la estética new romantic. Puesto que "Life on Mars?" era uno de los temas más glam de Bowie, la versión que hizo Casal es un buen ejemplo de la síntesis que proponía en Neocasal, entre el glam y la corriente que más claramente había recogido su testigo en los ochenta, los Nuevos Románticos.

\section{ETIQUETA NEGRA: "NEO-REALISMO ROMÁNTICO"}

El segundo trabajo de Casal, Etiqueta Negra, supuso la fijación de su estilo, que encontró en los Nuevos Románticos la corriente definitiva en la que enmarcarse. Al igual que Neocasal, Etiqueta Negra fue producido por Julián Ruiz y por la compañía EMI. El disco se publicó en 1983 y contiene algunas de las canciones de más éxito de Casal, por ejemplo, "Embrujada", que fue el primer single y de la que se llegó incluso a grabar una versión en inglés. ${ }^{35}$ Etiqueta negra supuso el despegue definitivo de la carrera de Casal y sus siguientes producciones serán, en cierta medida, una prolongación de las estrategias reflejadas en este álbum.

La new wave compartía con el punk su actitud de rebeldía, pero abrazaba los presupuestos warholianos de combinación del arte underground con los medios de comunicación de masas. Del mismo modo, el "nuevo pop" de sintetizador de los Nuevos Románticos abrazaba la comercialidad; así, aunque venían del punk no compartían su espíritu de independencia y anti-comercialidad. Como señala Dave Rimmer, era "como si el

\footnotetext{
${ }^{34}$ Cateforis, "Roll over Guitar Heroes, Synthesizers Are Here....", p. 2.

${ }^{35}$ La recepción que tuvo Etiqueta Negra fue tan positiva que posteriormente se lanzó una segunda edición que incluía la pieza "Tigre Bengalî", perteneciente a la banda sonora de Sal gorda, y, además de "Embrujada", se lanzaron varios singles, entre ellos "Póker para un perdedor" y "Los pájaros". Véase Vila, "Tino Casal. Tigre Bengalî", p. 38; y Quintana, Tino Casal: Más allá del embrujo, pp. 131-155.
}

punk nunca hubiera existido". ${ }^{36}$ No obstante, la influencia del punk puede apreciarse en la forma en que la new wave y los new romantics utilizaban el sintetizador. Al contrario que intérpretes como Keith Emerson, los new romantics rechazaban el virtuosismo, y en su forma de aproximarse al sintetizador mostraban una economía de recursos musicales que entroncaba con el espíritu amateurista del "hazlo tú mismo" (DIY - do it yourself) del punk.$^{37}$ Cateforis señala que, por ejemplo, Gary Numan, uno de los artistas de la new wave que más usaba el sintetizador, se sentía especialmente orgulloso de hacer una música que podía tocarse con digitaciones de un sólo dedo, dos a lo sumo, que requerían muy poca o nula destreza o técnica pianística. ${ }^{38} \mathrm{Casal}$ adoptó esta estética, utilizando el sintetizador de forma notable en toda su producción con la intención de generar una música bailable y de fácil escucha e interpretación, que podía ser ejecutada por cualquier amateur.

Lo primero que se aprecia en Etiqueta negra es la desaparición de las partes de guitarra, que era el instrumento que mantenía, en buena medida, el nexo de unión con el rock en Neocasal. En los temas del segundo disco no sólo no se incluye ningún solo de guitarra, sino que además los riffs pasan a ser ejecutados por el sintetizador, del que se encargaba Javier Losada. De este modo, el sintetizador comienza a ser el instrumento con mayor peso estructural: aporta el material principal y enlaza las distintas secciones de las piezas. Un buen ejemplo de ello es el pegadizo riff de "Embrujada", que se presenta al inicio y se va repitiendo a modo de enlace durante el resto del tema; véase Ejemplo 2. Este riff es fácil de ejecutar: repite varias veces una sola nota ( $\mathrm{Si}$ b), y puede ejecutarse fácilmente con una mano sin variar la posición.

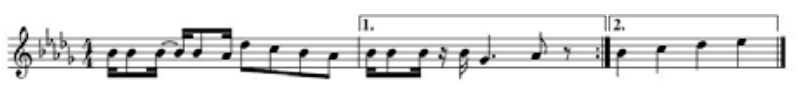

Ejemplo 2. Riff principal de "Embrujada", realizado por el sintetizador. ${ }^{39}$

${ }^{36}$ Rimmer, Like Punk Never Happened: Culture Club and the New Pop, p. 13.

${ }^{37}$ Cateforis, Are We Not New Wave? Modern Pop at the Turn of the 1980s, p. 168. Como señala Dave Laing, One Chord Wonders: Power and Meaning in Punk Rock (Oakland, CA: PM Press, 1985), el punk se erigía sobre una estética "minimalista" de producir temas con apenas tres acordes, que perseguía distanciarse del elitismo de corrientes como el progresivo, que se consideraban alejadas de lo que creían que era la esencia "popular" del rock: ser una música que todo el mundo puede tocar.

${ }^{38}$ Cateforis, Are We Not New Wave? Modern Pop at the Turn of the 1980s, p. 167.

${ }^{39}$ Aunque la transcripción del riff se ha realizado en la tonalidad que "suena" realmente, Si bemol menor, es probable que Casal lo compusiera con la guitarra afinada un semitono por debajo de la afinación estándar (Mi-La-Re-Sol-Si-Mi). Es decir, que Casal no habría pensado en una armonía con cinco bemoles, sino en Si menor, que sólo tiene dos sostenidos; así, los acordes con los que se construiría "Embrujada", 
Otro elemento importante de Etiqueta negra, que ya estaba en Neocasal, era el baile. A menudo, los riffs y los ritmos de las piezas de este disco contenían síncopas y notas a contratiempo que favorecían el baile; véase Ejemplo 2. El baile era un elemento que, como se ha señalado, impregnaba toda la new wave, y que suele valorarse más cercano al pop que al rock. ${ }^{40} \mathrm{El}$ baile también es favorecido por la percusión, que a menudo es electrónica, ${ }^{41}$ y el bajo. Por ejemplo, en las estrofas de "Azúcar Moreno" se puede observar cómo el carácter bailable de la pieza viene determinado por el juego entre las síncopas en el bajo y el golpe de la percusión en el registro alto en las partes débiles del compás; véase Ejemplo 3.

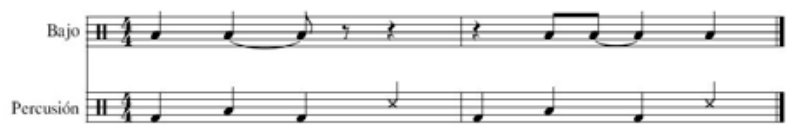

Ejemplo 3. Transcripción del ritmo del motivo del bajo y de la percusión en las estrofas de "Azúcar Moreno".

Casal va a preservar y a acentuar en Etiqueta Negra el aura de experimentación a través del uso manifiesto de tecnología "moderna" que había dejado entrever en Neocasal. El componente de la banda Video, José Manuel Moles, señalaba que Casal "siempre quería estar a la última", y Javier Losada explicaba que ellos llevaban "la tecnología más puntera: éramos los únicos que teníamos esos instrumentos". ${ }^{42}$ Casal juega con la búsqueda de "nuevos sonidos" en canciones como "Malaria" o "Miedo", donde distorsiona el material sonoro para producir efectos novedosos: "[a Casal] le gustaba manipular el sonido y conseguir algo distinto (...) por ejemplo, metíamos una caja de ritmos y la desafinaba aposta, (...) consiguiendo algo no convencional". ${ }^{43}$

Como hemos enunciado, Cateforis afirma que la new wave reflejaba el nacimiento de una nueva sensibilidad posmoderna. Según Lawrence Grossberg, la posmodernidad supuso en los ochenta "el colapso histórico" de la capacidad de invertir en

principalmente Si menor (I), Sol (VI) y La (VII), resultarían fáciles de ejecutar con la guitarra. Cabe señalar que afinar la guitarra un semitono por debajo es una práctica habitual dentro de las músicas populares urbanas y que suele deberse a cuestiones de comodidad tanto del canto (moviéndose a una tesitura más grave y, por tanto, cómoda para una voz masculina), como de la ejecución instrumental, ya que tocar en Si bemol menor implicaría realizar una considerable cantidad de acordes con cejilla, algo que puede llegar a ser incómodo para el intérprete.

40 Timothy Warner, Pop Music: Technology and Creativity - Trevor Horn and the Digital Revolution (Aldershot: Ashgate, 2003), pp. 14-15.

${ }^{41}$ Tino Casal solía hacer uso de cajas de ritmos Linn y baterías Simmons (Todo Casal, EMI, 2011).

${ }^{42}$ Quintana, Tino Casal: Más allá del embrujo, p. 132.

43 Javier Losada en Quintana, Tino Casal: Más allá del embrujo, p. 132. objetos y productos, y dotarlos de significado al volvernos conscientes de que ello supone su mitificación. ${ }^{44} \mathrm{La}$ sensibilidad posmoderna de los ochenta se habría erigido, pues, sobre la conciencia de que los productos culturales habían perdido su aura de "autenticidad", siendo todos igual de artificiales, falsos o inauténticos. La sensibilidad posmoderna se definiría, así, por una lógica de "nihilismo irónico" o "auténtica inautenticidad" ${ }^{45} \mathrm{El}$ hecho de que todas las imágenes se hubieran vuelto "igual de irreales" no negaría, sin embargo, la importancia de las mismas, pero habría inhabilitado la posibilidad de invertir en ellas de forma unívoca. En la nueva sensibilidad posmoderna, las imágenes se habrían vuelto más importantes que la realidad, más reales, y lo único que no se falsificaría sería el hecho de que se está falseando, lo que genera una "auténtica" o verdadera inautenticidad:

la auténtica inautenticidad es indiferente a la diferencia.... En su lugar, celebramos la ambigüedad afectiva de las imágenes.... Si cada identidad es igualmente una falsificación, una pose tomada, entonces la auténtica inautenticidad celebra las posibilidades de poses sin negar que eso es todo lo que son. ${ }^{46}$

Por su parte, Frederic Jameson señala que el elemento que define a la posmodernidad es el pastiche, "la imitación de un estilo peculiar o único, el uso de una máscara estilística, el habla en un idioma muerto", pero, al contrario que la parodia, supondría una "práctica neutral de mimetismo", desprovista del impulso satírico de la parodia. ${ }^{47}$ La práctica de hacer uso de estilos y productos de forma vacía, tratándolos como una máscara, como una imagen desprovista de significado y de "autenticidad" encajaría bien con la "auténtica inautenticidad" que propone Grossberg. Así, el ser "moderno" en la posmodernidad significaría celebrar lo "falso" y superficial - la imagen frente al contenido - , lo artificial y lo sintético ${ }^{48}$ lo que, como apunta Simon Reynolds, encajaría con el glam y explicaría por qué fue tan importante para los new romantics; "rechazando lo natural" por "lo antinatural, plástico y artificial", el glam habría estado ensa-

${ }^{44}$ Grossberg, "Rock, posmodernity and authenticity", pp. 221-222.

${ }^{45}$ Grossberg, "Rock, posmodernity and authenticity", pp. 224.

${ }^{46}$ Grossberg, "Rock, posmodernity and authenticity", pp. 225-226: "Authentic inauthenticity is in-different to difference.... Instead, we celebrate the affective ambiguity of images.... If every identity is equally a fake, a pose taken, then authentic inauthenticity celebrates the possibilities of poses without denying that this is all they are".

${ }^{47}$ Fredric Jameson, "Postmodernism and Consumer Society", The Anti-Aesthetic: Essays in Postmodern Culture (Port Townsend, WA: Bay Press, 1983), pp. 114: "Pastiche is, like parody, the imitation of a peculiar or unique style, the wearing of a stylistic mask, speech in a dead language but it is a neutral practice of mimicry, without parody's ulterior motive, without the satirical impulse, (...) Pastiche is blank parody, parody that has lost its humour".

${ }^{48}$ Grossberg, "Rock, posmodernity and authenticity", pp. 218. 
yando "la sensibilidad de lo que luego conoceríamos como posmodernismo". 49

La forma de utilizar el sintetizador en los años ochenta encajaba con este énfasis en lo falso o artificial de la sensibilidad posmoderna. Como señala Cateforis, los músicos de la new wave pretendían no imitar fielmente sonidos reales, sino producir unos nuevos que parecieran claramente una copia artificial y electrónica de estos. ${ }^{50}$ Así, a través del sintetizador los músicos pretendían dar una imagen de artificio o falsificación que se percibía como moderna al reflejar el sino de la época. Los new romantics superponían la "futurista" y artificial música electrónica del synth pop a un conglomerado de referencias visuales "románticas"; esto producía un efecto de imitación falseada y de pastiche que reflejaba la moderna sensibilidad del momento. ${ }^{51}$ Los Nuevos Románticos, aunque seguían invirtiendo en las imágenes de evasión nostálgica propias del Romanticismo, las desproveían de su halo de autenticidad al unirlas con el artificio del sintetizador. Mediante esta estrategia, los Nuevos Románticos añadían connotaciones de artificio al Romanticismo y lo convertían en una imagen artificial, un cliché vacío y sin contenido.

La estética new romantic no sólo hacía uso de la práctica del pastiche y reflejaba la "auténtica inautenticidad" posmoderna, sino que encajaba también con lo que Kleinhans denomina "kitsch autoconsciente". Kleinhans señala que "a menudo, los objetos culturales contemporáneos son altamente autoconscientes de su propia condición de degradación",;2 aunque sabemos que el valor del kitsch es una fantasía, una imagen falseada, disfrutamos de la diversión que provoca su fenómeno. Artistas new romantics, como el propio Casal, invirtieron en el kitsch de forma consciente, ya que el kitsch encajaba bien con la inversión en la inautenticidad que llevaba a cabo la sensibilidad posmoderna, y que era el eje en torno al cual la new wave y los new romantics articulaban su discurso de modernidad.

A nivel visual, Casal ya había adaptado el discurso de los Nuevos Románticos en Neocasal, y siguió utilizándolo a través de su pastiche "posmoderno" y recargado de referencias a lo

${ }^{49}$ Simon Reynolds, Retromania: Pop Culture's Addiction to Its Own Past (Londres: Faber and Faber, 2011), p. 9: "Shunning the natural, organic and wholesome in favour of the unnatural, plastic and artificial, glam essentially rehearsed the sensibility of what we would later know as postmodernism".

${ }^{50}$ Cateforis, Are We Not New Wave? Modern Pop at the Turn of the 1980s, p. 162.

${ }^{51}$ Por ejemplo, los mencionados Soft Cell en su videoclip de "Tainted Love" mezclaban las referencias a la antigua Roma y la Belle Époque con el pegadizo synth pop del momento. Puede visionarse dicho videoclip en: Soft Cell, "Soft Cell - Tainted Love - Original Video", Youtube: <https://www.youtube.com/watch?v=-KTaNnPfkfU>, consultado el 12 de septiembre de 2019.

${ }^{52}$ Chuck Kleinhans, "Taking Out the Trash Camp and the Politics of Parody", en The Politics and Poetics of Camp, ed. Moe Meyer (Londres: Routledge, 1994), pp. 183: "Contemporary culture objects are often highly self-conscious of their own debased status. I will call this self-aware kitsch". largo de toda su carrera; véanse Figuras 1 y 5 . Así, Joan Singla en Popular 1 señalaba que, a su juicio, Casal producía "un verdadero shock gracias a su elegante y a la vez súper-moderna imagen" ${ }^{53}$ En el plano musical Tino Casal también sigue la sensibilidad posmoderna de los new romantics utilizando el pastiche y el kitsch de forma manifiesta y consciente. El kitsch era una parte importante de la propuesta de Casal; Bernardo Baragaño señalaba que Casal tenía "una refinada estética kitsch" ${ }^{54}$ El kitsch está presente en Etiqueta negra en temas como "Los pájaros"; en este, Casal factura un clímax basado en la adición de elementos y el aumento de la textura, estrategia usada por las power ballads. ${ }^{55}$ Casal introduce en la segunda mitad de "Los pájaros" unos grandilocuentes coros que, unidos al artificial y manido sonido futurista del Theremin, producen una sensación de artificio kitsch "moderno" y de recargamiento "barroco", un término que a menudo se ha utilizado para referirse a Casal. ${ }^{56}$

Otro buen ejemplo del discurso new romantic que Casal pone en marcha en Etiqueta negra es el tema "African chic"; en él utiliza un exotismo kitsch y "futurista" que se puede observar en otros cortes del disco como "Tigre Bengalî" o "Malaria", y que sigue la estela de artistas del momento como Toto (en su tema "Africa") o Bowie (en "African Night Flight"). En "African chic" Casal utiliza el exotismo asociado con la referencia a una cultura ajena introduciendo coros pseudo-africanos realizados por el grupo Guinea. Casal mezcla estos coros con experimentos "vanguardistas" ya vistos de modificación de la voz. ${ }^{57}$ La referencia tanto a otras culturas, como a un futuro de progreso, es vista a través del prisma de la inautenticidad y del kitsch; ninguno de los dos, ni los coros "tribales", ni la "innovación" de los procesamientos tecnológicos de la voz son totalmente creíbles. Ambos son estereotipos de cuya falsedad somos conscientes: África y primitivismo; futuro y máquinas. A pesar de ello, estos estereotipos seguirían produciendo disfrute porque en ellos reconocemos los mecanismos internos de nuestra cultura. La utilización consciente del kitsch, que puede apreciarse en este tema de Casal, sería, como señala Kleinhans, una vía para reconocer nuestra propia idiosincrasia - la "auténtica inautenticidad" de nuestros relatos culturales - al tiempo que seguimos disfrutando de ella. ${ }^{58}$ Por eso, "African chic" es un buen ejemplo de cómo la estética new romantic de Casal reflejaba la modernidad posmoderna.

\footnotetext{
53 Singla, "Neo-realismo romántico", p. 71.

${ }^{54}$ Lara González, ed., Oro Negro: 25 años sin Tino Casal (Madrid y Vizcaya: Grafilur, 2016), p. 204.

${ }_{55}$ David Metzer, “The power ballad", Popular Music, $31 / 3$ (2012), p. 439.

${ }^{56}$ Por ejemplo, Quintana, Tino Casal: Más allá del embrujo, p. 140, opina que Casal estaba "siempre enmarcado dentro de lo kitsch y lo barroco".

${ }^{57}$ Quintana, Tino Casal: Más allá del embrujo, p. 145.

${ }^{58}$ Kleinhans, "Taking Out the Trash Camp and the Politics of Parody", p. 183.
} 
Keir Keightley distingue dos formas de articulación de la autenticidad en el rock: una romántica y otra modernista. ${ }^{59} \mathrm{~A}$ pesar de la utilización a nivel visual de imágenes románticas, los new romantics encajaban bien en la "modernista"; esta celebra la experimentación y la tecnología, y es más abierta en la consideración de qué sonidos se pueden denominar rock. Los new romantics aunque utilizan el artificio de los sonidos de sintetizador podrían participar de este tipo de autenticidad por la experimentación asociada al uso de tecnología. ${ }^{60}$

Casal buscaba que su propuesta fuera "fuerte" y provocadora a nivel visual y musical, y que colmara los deseos del público, que esperaba de él "ver algo nuevo, (...) algo diferente" ${ }^{61}$ Las connotaciones de experimentación que Casal trató de infundir a su discurso daban legitimidad y autenticidad a su propuesta: enlazaban tanto con la modernidad de la new wave, como con las ansias de innovación de cierta parte del rock. Casal se percibía como "adelantado" a su época, "vanguardista" e innovador, ${ }^{62}$ y actualizado con el "adelantado" y moderno pop y rock anglosajón. ${ }^{63}$ Casal fue aceptado por círculos afines al rock a pesar de que su música era, en gran medida, pop bailable y comercial. Por ejemplo, Paco Laguna, de la banda de heavy Obús - a quienes Casal había producido-, declaraba que Casal "siempre estuvo cercano al rock", ${ }^{64}$ y en Rock Espezial, el crítico García Puig, aun admitiendo que Casal hacía "un producto sofisticado, pero fácilmente digerible", señalaba que era "una obra importante en la historia del rock de aquî" ${ }^{55}$ Por tanto, podría decirse que el discurso que propone Casal a partir de Etiqueta Negra, a pesar de la eliminación de elementos "clásicos" del rock como la guitarra, podría participar de su tipo de autenticidad modernista.

Casal no creaba personajes, sino que presentaba un discurso en el que su extravagante estética le representaba a él mismo. Casal vestía igual sobre el escenario que caminando por la

${ }^{59}$ Keir Keightley, "Reconsidering rock", en Cambridge Companion to Pop and Rock, ed. Simon Frith, Will Straw y John Street (Cambridge: Cambridge University Press, 2001), p. 137.

${ }^{60}$ Por ejemplo, Ultravox en una entrevista señalaban: "hemos establecido que somos un grupo de rock (...) Tratamos de ser equilibrados. Experimentamos con los solos de guitarra (...) y con lo electrónico. Así que somos un grupo de rock que usa sintetizador"; véase Chris Welch, "Ultravox", Popular, 1/90 (Barcelona, diciembre de 1980), pp. 74-77.

${ }^{61}$ Godes, "Casal: Locura o histeria", p. 35.

${ }^{62}$ Carlos Taboada, "El hallazgo de Tino Casal", El Gran Musical, 206 (Madrid, abril de 1981), p. 17, señalaba que Neocasal era "un álbum de vanguardia", mientras que Singla, "Neo-realismo romántico", pp. 71-72, anunciaba: "Atención a esta nueva personalidad en el mundo de la música hispánica, su sonido es contundente e innovador".

${ }^{63}$ En palabras de Tino Casal: "a todo el mundo le costaba aceptarme. (...). El problema era que la gente no creía lo que veía, pensaba que yo venía de fuera, del extranjero, y no le cabía en la cabeza que yo pudiera ser español (...)"; véase Vila, “Tino Casal. Tigre Bengalî”, p. 38.

${ }^{64}$ González, Oro Negro: 25 años sin Tino Casal, p. 214.

${ }^{65}$ Damián García Puig, "Casal. `Neocasal'. EMI”, Rock Espezial, 5 (enero de 1982), p. 53. calle, proyectando el mensaje de que no iba disfrazado en escena, sino que era un vestuario que reflejaba su personalidad. Esta estrategia contribuía también a aportar legitimidad a su discurso. La prensa creía que la recargada y artificiosa imagen de Casal iba vinculada "con la creación, que es lo primero", representaba su mundo, sus "apetencias" y lo que le gustaba: "Casal llegó vestido de lo que quiso, (...) y convirtió su habitual modo de vida en motor de su futura obra. Nada era pose. (...) lo suyo era un modo de vida". ${ }^{66}$ La utilización del artificio y el kitsch, lo "hortera", no se vio penalizada, ya que se percibía autenticidad y "honestidad" creativa en su manera de articularlo. ${ }^{67}$

Como hemos expuesto, el uso del artificio y el kitsch por parte de Casal encajaba con la modernidad posmoderna que impregnaba los tiempos que se estaban viviendo; quizá por ello, el periodista Joan Singla creía que lo que Casal facturaba era un "neo-realismo romántico". ${ }^{68}$ La fidelidad con que la propuesta new romantic de Casal reflejaba el contexto cultural del momento y su identificación personal con ella hacían que el uso del artificio y el kitsch no perjudicara a su legitimación. La crítica percibía a Casal como un modelo de "artista total" (cantante, compositor, productor, pintor, diseñador, etc.), un "esteta" que combinaba con profesionalidad, legitimidad y "realismo", la música y las artes visuales. ${ }^{69}$

un artista que domine la técnica de un cantante, que componga con una inteligencia musical fuera de la normalidad (...) que maneje la pintura, la expresión corporal, cualquier rama artística (...) Tino Casal es un Artista, así, con mayúscula. $^{70}$

\section{HIELO ROJO: CONTINUIDAD Y ASENTAMIENTO DE LA PROPUESTA DE CASAL}

Tras el éxito de Etiqueta negra, aparece al año siguiente el álbum Hielo rojo (EMI, 1984), que supone una pasarela en la propuesta artística de Casal, que aquí ya queda conformada hasta Lágrimas de cocodrilo. Como veremos a continuación, en Hielo rojo Tino Casal desarrolla ideas que valoramos en sus anteriores trabajos discográficos. Hielo rojo contribuyó a afianzar la popularidad de Casal gracias a que uno de sus temas, "Pánico en el Edén”, fue escogido como canción oficial de la Vuelta Ci-

${ }^{66}$ Manoteras-Maiquez, "Glamoures del underground: All that Kitsch”, La Luna de Madrid, 16 (Madrid, marzo de 1985), pp. 38-39; y anónimo, “¡Hasta siempre, Tino!”, El Gran Musical, 349 (Madrid, octubre de 1991), pp. 36-37.

${ }^{67}$ Por ejemplo, en Rockdelux, 80, “Tino Casal: El último rey del Glam..." (noviembre de 1991), p. 21, a raíz de su muerte, se señalaba: “...para muchos [Casal] era un hortera. Sí, lo era. ¿Y qué? ¿Acaso ser hortera no puede llegar a tener su encanto? (...) A Tino Casal le gustaba ir de hortera. (...) Se creó una imagen de glamour con la que se sentía identificado".

${ }^{68}$ Singla, "Neo-realismo romántico", pp. 71-72.

${ }^{69}$ García Puig, "Casal. `Neocasal'. EMI”, p. 53.

${ }^{70}$ Taboada, "El hallazgo de Tino Casal", p. 17. 
clista a España en 1984. Sin duda, este fue el gran éxito del disco, permaneciendo ocho semanas en la lista de los diez sencillos más vendidos en España ese año, y apareciendo en versión maxi - Más pánico en el Edén-, junto con otros cuatro temas del disco.

Con toda probabilidad, las letras, más sugerentes y personales, suponen uno de los mayores atractivos de este tercer álbum. Prueba de ello es "Mañana", con un texto casi "profético", al introducir temas cibernéticos y sobre conflictos internacionales, a modo de carta futurista dedicada al hijo del tour manager de la banda. Se trata de una especie de texto predictivo con cierto halo de misterio y esperanza, que subraya el ambiente de experimentación sonora, vista también en anteriores discos, con la introducción de la caja de ritmos analógica Roland - probablemente la Roland TR-66, si bien los créditos del álbum no lo especifican - que ya habían utilizado Roxy Music, en temas como "Dance away" del álbum Manifesto (1979), y otras bandas de la new wave.

Casal continúa en Hielo rojo con la búsqueda de efectos sonoros en un ejercicio de experimentación e innovación musical, que ya vimos en sus anteriores discos, a través del uso de la tecnología. En varios temas de este album, como "Pánico en el Edén", destaca el uso del sampler Fairlight CMI (Computer Music Instrument) que Casal utilizó de manera pionera en España y que permitía utilizar sonidos grabados y modificarlos para generar nuevas texturas, revolucionando así la utilización del sampler en las décadas de 1970 y $1980 .{ }^{71}$ El Fairlight CMI fue una de las primeras estaciones con un sintetizador de muestreo digital integrado, que incorporaba el primer secuenciador musical gráfico en tiempo real, lo que demuestra la "obsesión" de Casal por utilizar tecnología a la última. La amalgama de sonidos electrónicos destaca en piezas como "Loco suicida", "Bailar hasta morir" o "Pánico en el Edén”. La evolución de Tino Casal hacia un universo sonoro cada vez más denso queda patente en Hielo rojo en temas como "Bailar hasta morir", que muestran una adición progresiva de elementos que culminan en un final recargado y en los que la maquinaria electrónica está siempre presente. $^{72}$

Hielo rojo sigue reflejando, asimismo, el gusto por lo visual y la concepción de Casal de sus producciones como una amalgama de disciplinas artísticas. Por ejemplo, las imágenes

\footnotetext{
${ }^{71}$ El productor Julián Ruiz explica que este muestreador sólo lo tenía entonces Josep Maria Mainat i Castells, del grupo humorístico musical La Trinca, quien les ayudó en la producción de Pánico del Edén. Véase <https://www.plasticosydecibelios.com/historia-canciones-tinocasal-por-julian-ruiz/>, consultado el 23 de marzo de 2018.

${ }^{72}$ Según se recoge en los créditos del disco, Javier Losada se encargó del manejo del Fairlight II, junto con Mainat, además de tocar los Yamaha DX7, Emulator y Júpiter 8 Roland. Paco Palacios aparece encargado de las guitarras Fender y Roland, mientras que Manuel Aguilar tocó un bajo Fender sin trastes y Stick. Por su parte, Javier de Juan fue el programador del Linn 2 y Simmons, y Tino Casal tocó la Drumbox Roland. De la mezcla se encargó el ingeniero de sonido de Sony, Luis Fernández Soria.
}

de la carpeta muestran detalles de complementos de moda confeccionados por el artista. Casal resalta el brillo de los guantes y los pendientes; ello está en relación con la estética glam que, como mencionamos, fue determinante para Casal en sus inicios. Destaca también la influencia de otros iconos neorrománticos del momento, como Boy George o Adam Ant. ${ }^{73}$ El gusto de Casal por los gorros o los peinados con rastas que luce en el videoclip de "Bailar hasta morir" conecta con los looks de Hazy Fantayzee. De igual forma, la foto de portada del doble recopilatorio póstumo Casal Vive (EMI-Odeón, 2000), con un Casal rodeado de telas y brillos en primer plano, recuerda a imágenes de Steve Strange, líder de la banda electrónica new romantic Visage. Con ello, puede afirmarse que en este momento el estilismo de Casal, dentro de su imagen camaleónica, llega al clímax en lo que respecta a su adaptación de la extravagancia y el artificio de los new romantics. Esto se aprecia claramente en el videoclip de "Bailar hasta morir", que muestra al artista con sus ropajes en la entrada del hotel Plaza.

\section{LÁGRIMAS DE COCODRILO: LA REAPARICIÓN ESTELAR DE CASAL}

Después de pasar por un periodo de aislamiento debido a problemas médicos, Casal reaparece en la escena española a todo lujo con el álbum Lágrimas de cocodrilo (EMI-Odeón, 1987). Se muestra recuperado de su enfermedad, una necrosis provocada por un esguince mal curado que, junto con otros problemas de salud, había provocado especulaciones en la prensa acerca del estado del artista a mediados de la década de $1980 .{ }^{74}$ En Lágrimas de cocodrilo, Casal presenta los modelos más rompedores y recargados a nivel visual y musical de su carrera, lo que podría considerarse como el clímax de su uso del kitsch. Este es combinado con un despliegue de teatralidad, al estilo del modo performativo showing doing que Auslander aplica al glam. ${ }^{75}$ Esta estética de lo desmesurado incorpora un extravagante y ecléctico caos ordenado que, en la línea de lo indicado más arriba, articula un "kitsch autoconsciente" que representa el sino de la posmodernidad. No en vano, el propio artista afirmaba, ya en 1990, que prefería vivir "como en el carro de una pitonisa; es más cómodo vivir rodeado de cosas que alegran la retina que en una casa convencional". ${ }^{76}$ La portada de Lágrimas de

\footnotetext{
${ }^{73}$ Andrés López Martínez, Historias, excesos y tribulaciones de la mal llamada música gay (Lleida: Milenio, 2010).

${ }^{74}$ Los diarios y revistas informaron acerca del ingreso de Tino Casal en la Unidad de Vigilancia Intensiva (UVI) del Hospital del Rey de Madrid en agosto de 1985. Durante los meses siguientes la prensa aclaró su diagnóstico, en el que confluían el problema en el fémur izquierdo - por el que Tino tuvo que ser operado-, un grave cuadro hepático, debido a la medicación para el dolor de la pierna, y una intoxicación por salmonelosis; véase C. Jaro, "Tino Casal: 'He visto la muerte muy de cerca'”. Pronto, 713 (Madrid, 6 de enero de 1986), pp. 6-7.

75 Auslander, Performing Glam Rock: Gender and Theatricality in Popular Music, p. 101.

${ }^{76}$ Erice, "Tino Casal. Observándose en el espejo", pp. 8-9.
} 
cocodrilo, donde aparece un Casal regente, sentado en su sillón y rodeado de pieles, refleja bien esta estética y quizá por ello se ha convertido en una de las imágenes más icónicas del artista; véase Figura 5. La fotografía se corresponde con las imágenes del videoclip de "Oro negro", que fue el segundo single del álbum, junto con "Santa Inquisición".

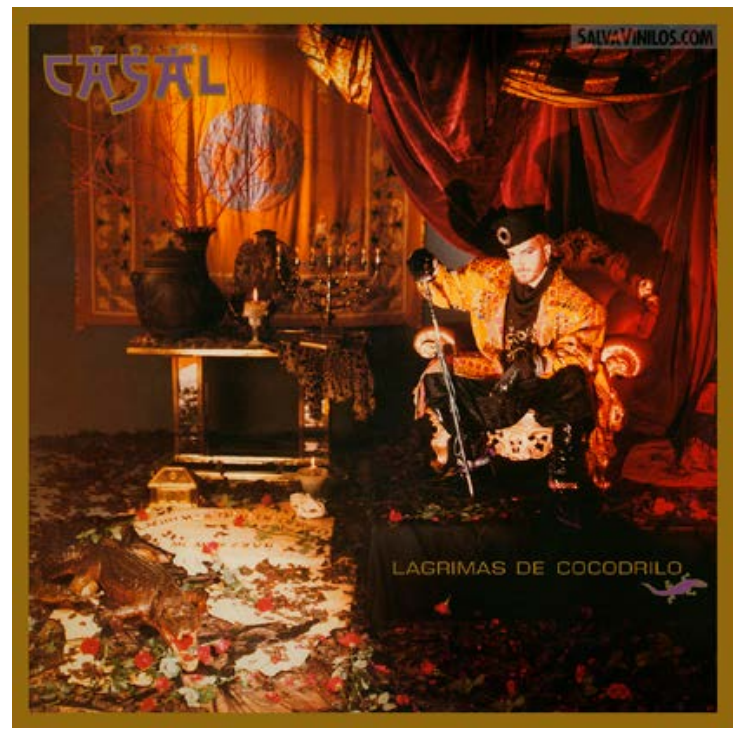

Figura 5. Imagen de la portada del álbum Lágrimas de cocodrilo de Casal.

Las imágenes del video de "Oro negro" destacan por la riqueza de detalles, el exceso, los elementos simbólicos, y una estética recargada y glamurosa. Hay, además, una iconografía particular, la salamandra, que enlaza los fotogramas de aparición de la banda con los de Casal en el videoclip. La salamandra es símbolo de constancia, pero también de la castidad, y en el Renacimiento era considerada un animal asexual, ${ }^{77}$ lo que conectaba con la androginia del glam y los new romantics. Casal aparece en el video con varias capas de ropa sin dejar prácticamente piel descubierta y con bronceado, además de con perilla y bigote, signos ambos de masculinidad que ya lucía en años anteriores. La imagen de Casal destaca por basarse en modelos de diseño propio, siguiendo con su inclinación por las artes visuales que señalamos en apartados anteriores, elaborados con telas espectaculares y complementos vistosos que enfatizaban las connotaciones de artificio de su propuesta. Asimismo, es en el año de Lágrimas de cocodrilo cuando Casal incluye el popular bastón. ${ }^{78}$ En este punto, conviene recordar que Casal consi-

${ }^{77}$ Federico Revilla, Diccionario de iconografía y simbología (Madrid: Cátedra, 2009), p. 589.

${ }^{78}$ Véase Juan Gutiérrez, Tino Casal. El arte por exceso (Madrid: Ministerio de Educación, Cultura y Deporte, 2017). deró el vestuario como un factor fundamental para aportar autenticidad "modernista" a su propuesta. Como declaraba el propio Casal: "en la calle aprendí a ser chocante, me extrañaría muchísimo que la gente no me mirara y me dejara pasar como a una persona normal y corriente, entonces sí que notaría que me falta algo". ${ }^{79}$ Esto conecta con nuestra idea de que el discurso de Casal está impregnado de una estética kitsch que caracteriza a la posmodernidad, en una labor sincrética, de práctica del pastiche, que reconocía el propio artista al definir su música como "una ensaladilla rusa". Casal señalaba que "el kitsch es como la mayonesa, por muchos ingredientes que acumules al final es ella la que determina el sabor", ${ }^{80}$ lo que viene a confirmar no sólo que el kitsch es el elemento en torno al que se articulaba su discurso, sino también que lo utilizaba de forma consciente.

A nivel musical, Lágrimas de cocodrilo es un disco más homogéneo que los trabajos anteriores del artista, y tuvo especial difusión gracias a temas de éxito como "Eloise". Este, que fue su primer single, estaba grabado en los estudios londinenses de Abbey Road. Se trata de una versión del clásico de 1968 cantado por Barry Ryan y que el grupo británico The Damned otra de las referencias de Casal - había recuperado en 1986. La pieza facilitaba la demostración de las cualidades vocales de Casal, lo que es una constante en Lágrimas de cocodrilo, y un rasgo que lo diferencia del anterior álbum que se observa también en "Oro negro": "Oro negro" y "Eloise" incluían unos llamativos giros hacia el agudo que favorecían el lucimiento de Casal como cantante. Casal destacaba también "Oro negro" por lo sofisticado de su producción, con unos arreglos facturados con sintetizadores, mezcladores y sampleadores, que combinaba con instrumentos más "clásicos" como la batería o la guitarra eléctrica. ${ }^{81}$ En los arreglos se incide en la estrategia del aumento de la densidad textural a través del añadido progresivo de instrumentos, que valoramos ya en piezas como "Los pájaros", y que puede observarse especialmente en los estribillos finales. La estructura de "Oro negro" es simétrica, incluso cíclica, si tenemos en cuenta el juego de ecos vocales que abre y cierra el tema.

Otra práctica que se repite en las canciones de Casal de este disco es el empleo de una introducción a cargo del sintetizador con material musical significativo que sirve de base para la conducción del tema. Esto es algo que ya habíamos apuntado en relación con piezas como "Embrujada". Así, "Oro negro" comienza con un motivo que servirá para dar unidad a la canción (véase Ejemplo 4); este reaparece en la parte central, antes de la segunda estrofa, y en variaciones a modo de contra-temas en el desarrollo. Ello, unido a la oposición de registros en la

${ }^{79}$ Erice, "Tino Casal. Observándose en el espejo”, pp. 8-9.

${ }^{80}$ Manoteras-Maiquez, "Glamoures del underground: All that Kitsch",p. 38

${ }^{81}$ Según los créditos del disco, en "Oro negro" se emplearon un teclado Kurzvell, con sistema Synergy, además del Emulator y el similar Prophet 2000, Akai, Linn 9000, Studio 440, Atari, Mirage, DX-7, Prophet V, Júpiter-8, JXP Roland, Mini moog, guitarras Fender, y batería Staccato y Ludwig para el sampling. 
textura, puede relacionarse con un gusto por los contrarios, que se refleja además en la letra ("Tú tan natural, yo tan especial", "Tú la exactitud, yo la densidad", "Oro negro, oro blanco") y que entronca con ese otro elemento característico de la propuesta de Casal heredado del glam y los Nuevos Románticos: la ambigüedad.

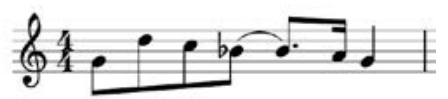

Ejemplo 4. Motivo inicial de Oro negro.

\section{1990 HISTERIA: UN GIRO INTERRUMPIDO EN LA EVOLUCIÓN MUSICAL DE CASAL}

1990 Histeria, el último LP de Tino Casal (EMI-Odeón, 1989), supuso un giro en su propuesta musical para abrir la nueva década; no tuvo la misma difusión que discos anteriores y presentaba a un Casal cada vez más volcado en las artes plásticas. Con toda probabilidad, 1990 Histeria supuso un punto de inflexión en la evolución musical del artista, quizá por el agotamiento de las propuestas de los new romantics, de las que, como hemos visto, él se servía, y que ya eran una tendencia superada en los noventa. El final de la década de 1980 supuso un momento de reflexión para Tino Casal; esto se aprecia, como veremos, en las letras de las canciones de 1990 Histeria. Casal afirmaba en este momento que "para llegar a la simplicidad con cierta magia primero es necesario haber rebuscado mucho"; ${ }^{2}$ quizá por ello, 1990 Histeria es un trabajo más unitario y sencillo musicalmente que otros discos.

Es necesario tener en cuenta los cambios que hubo en el ambiente madrileño: se disolvía entonces el grupo que se había formado en torno a Casal y a su inseparable amigo Fabio McNamara. No olvidemos también la pérdida en 1989 de Enrique Naya y Juan José Carrero, "Las Costus", cuya casa había representado una especie de "Factory" warholiana para el intercambio cultural entre artistas vinculados a la Movida madrileña. ${ }^{83}$ Casal dedicó a Las Costus su versión en 1990 Histeria de la canción "Don't you want me" de 1981 del grupo new romantic The Human League. En su adaptación, que Casal tituló "No fuimos héroes", modificó íntegramente la letra; en ella combinaba el recuerdo de años de juventud, con la referencia a creencias truncadas por el paso del tiempo, y el reflejo de cierto desencanto vital. Así, el texto señala: "No, no fuimos héroes / ya todo estaba escrito / mutilaron nuestros sueños. / No, no fuimos héroes / se mueren nuestros mitos / heredamos un infierno". De este modo, a través de esta versión, Casal afianza su encuadre dentro del synth pop y los Nuevos Románticos, y refleja el ca-

\footnotetext{
${ }^{82}$ Erice, “Tino Casal. Observándose en el espejo”, pp. 8-9.

${ }^{83}$ Vaquerizo, Fabiografía: Fabio McNamara.
}

rácter reflexivo de 1990 Histeria gracias a la nueva letra. Esto puede apreciarse también en la revisión que hace de la canción de Roberta Flack de 1973 "Killing me softly with his song" en dos cortes del disco. Casal la renombra "Tal como soy" y elimina el estilo jazzístico de la original mientras canta a un amor pasado con nostalgia: "Náufragos de un mar de dudas / navegaremos los dos / víctimas de esta locura / poco frecuente / de un amor contra corriente / ten valor y quiéreme siempre / tal como soy". Otro ejemplo de letra nostálgica y reflexiva se halla en "Destino casual", que señala: "Sin prisas por triunfar / sin miedo a fracasar / algo cansado / ya que tú no estás aquí. / Como un rebelde más / hambriento de algo más / un hechicero / con un destino casual".

Paralelamente, es significativo cómo 1990 Histeria es un disco más pausado, con un registro que tiende menos al virtuosismo vocal, aunque Casal no deja de buscar la variedad tímbrica en la producción del disco. Se perciben algunos puntos comunes en los timbres de la percusión de "Vanidosa" y "Voy a apostar por ti". También se escucha una preferencia por los ritmos irregulares y el baile ("Destino Casual", "Corazón bimotor"), presente en discos precedentes. Sin embargo, lo que distingue a 1990 Histeria es que la guitarra eléctrica recupera parte del protagonismo; por ejemplo, en el riff que sirve de enlace en "Vanidosa" y, sobre todo, en "Sex o no sex", ambas con referencias sexuales en sus textos. Hay que destacar la influencia en la base de "Sex o no sex" de la canción de Gary Glitter "Rock and Roll (parte 1)" de 1972, que precisamente, The Human League habían versionado en 1980. Así, las referencias simultáneas al glam y a los new romantics vuelven a estar presentes. En cierto modo, con "Sex o no sex" Casal remite también a la estética del glam metal, vigente a mediados de la década de 1980, que facturaba un tipo de metal ligero y "lúdico", y cuyas letras se caracterizaban, precisamente, por la híper-sexualización. ${ }^{84}$

El giro de Casal en la producción de 1990 Histeria remite a sus primeros trabajos discográficos, siendo necesario valorar la colaboración de Paco Palacios, iniciada en Hielo Rojo, en la parte de las guitarras y en la programación. ${ }^{85}$ En este caso, desaparece parte de la maquinaria de teclados y sintetizadores, aunque no se renuncia a las cajas de ritmos, los samplers y el sincronizador. Es evidente que en 1990 Histeria Casal se planteó

${ }^{84}$ Robert Walser, Running with the Devil: power, gender, and madness in heavy metal music (Hanover, NH: University Press of New England, 1993); Anya Kurennaya, "Look What the Cat Dragged in: Gender, Sexuality, and Authenticity in 1980s Glam Metal", trabajo de Fin de Master, Master of Arts in Fashion Studies (Nueva York: Parsons School of Design, The New School, 2012); Sara Arenillas Meléndez, Discursos, identidades y transgresión en la música popular española (1980-2010): el caso del glam rock y sus variantes, tesis doctoral (Universidad de Oviedo, 2017).

${ }^{85}$ El guitarrista y compositor alcalaíno Paco Palacios (1957-1993) trabajó para artistas como Tino Casal, Santiago Auserón, Hilario Camacho o Luz Casal, si bien logró especial reconocimiento junto a Miguel Ríos, sobre todo al participar en el álbum grabado en directo en el antiguo Pabellón de Deportes del Real Madrid, Rock and Ríos (1982). 
un disco "nuevo", más global, afirmando que le apetecía "un éxito difícil" ${ }^{86}$ Como hemos apuntado, Casal se muestra más reflexivo y realista en las letras, pero no pierde el énfasis en la fantasía inherente al artificio y el kitsch, que había caracterizado su discurso; por ejemplo, en sus declaraciones a la prensa afirmaba "dejo jugar a la ficción porque también forma parte de mí mismo" ${ }^{87}$ Asimismo, llama la atención la importancia que sigue concediéndose al aparato visual del artista, reconociéndole aún más por su extravagante imagen que por su música. No obstante, no parece que Casal viera esto de forma negativa, ya que en una entrevista de la época puntualizaba: "ser famoso por la forma de vestir también tiene su mérito" ${ }^{88}$

El giro musical que supuso 1990 Histeria quedó interrumpido con el accidente de coche que terminó con la vida de Tino Casal el 22 de septiembre de 1991. En años posteriores, su recuerdo se fue disipando entre las nuevas generaciones, seguramente debido a la obsolescencia del discurso new romantic en los noventa. A pesar de ello se siguieron editando álbumes recopilatorios y remixes desde 1992, como Etiqueta negra: Grandes éxitos y, hasta 2016, con De la piel del diablo: La colección definitiva ${ }^{89}$ Con la llegada del año 2000 y de lo que Simon Reynolds denomina como "retromanía" (2011), la estética posmoderna de nostalgia futurista de la new wave volvió a estar de actualidad, lo que facilitó la puesta en valor de nuevo del artista. ${ }^{90}$

\section{CONCLUSIONES}

Tino Casal fue un artista con gran difusión en la década de los ochenta. Lo más destacado de su producción fue la introducción en España de la corriente de los new romantics. En su debut, Casal mezclaba el discurso de los new romantics con el del glam. Tanto el glam como los new romantics eran corrientes en las que Casal - que sentía inclinación por la pintura, el diseño de moda o la decoración - se sentía cómodo por su énfasis en lo visual y el artificio. En cuanto a su evolución como artista, destacamos el cambio que Casal realizó en Etiqueta Negra, siendo en este disco en donde comienza a percibirse una pro-

${ }^{86}$ Erice, "Tino Casal. Observándose en el espejo”, pp. 8-9.

${ }^{87}$ Erice, "Tino Casal. Observándose en el espejo", pp. 8-9.

${ }^{88}$ Godes, "Casal: Locura o histeria", p. 35.

${ }^{89}$ Cerca de cumplirse el $25^{\circ}$ aniversario de su muerte, el periodista Gerardo Quintana publicó en 2007 una completa biografía del artista que, junto con el documental dirigido por José Antonio Quirós - Gran Casal: me como el mundo (Barcelona: Cameo Media, 2004) - , siguen siendo la referencia fundamental a la hora de acercarse a su historia. Hay que destacar, asimismo, la existencia en internet de blogs y fanpages donde la figura y la labor de Casal son recordadas de forma constante, por ejemplo, el grupo de Facebook Tino Casal Club <https://www. facebook.com/groups/132396420191692/>, consultado el 3 de abril de 2018.

${ }_{90}$ Véase Theo Cateforis, "Epilogue: the new wave revival", Are We Not New Wave? Modern Pop at the Turn of the 1980s (Ann Arbor: University of Michigan Press, 2011), pp. 217-23. puesta plenamente new romantic. Desde entonces, los trabajos de Casal adquirieron mayor homogeneidad, y estuvieron marcados por un ecléctico horror vacui de inclinación kitsch, el predominio de la tecnología de sintetizador y el baile.

La propuesta musical de Casal confeccionaba un pop de sintetizadores (synth o techno pop), bailable y pegadizo, similar al de los new romantics anglosajones. Los Nuevos Románticos no rechazaban la comercialidad; esto explica que Casal pudiera combinar fácilmente cierto aire de innovación sonora asociada al uso de la electrónica, con una amplia difusión y un elevado número de ventas. A través del uso de la tecnología "avanzada" del sintetizador, Casal pretendía dar una imagen moderna y futurista, al tiempo que imprimía un carácter de experimentación a su propuesta que entroncaba con la "autenticidad modernista" que Keir Keightley atribuye a parte del rock. En el plano visual, Casal recogía la estética recargada, extravagante y llamativa del glam y los new romantics, y recurría, como estos últimos, al conglomerado de imágenes "románticas" de evasión hacia el pasado, el futuro y lugares "lejanos".

Los Nuevos Románticos que Casal tenía como referencia formaban parte de la new wave que, según Cateforis, se caracterizaba por articular una modernidad posmoderna, en la que la "auténtica inautenticidad" (Grossberg), el pastiche (Jameson) y el "kitsch autoconsciente" (Kleinhans) tenían cabida. A través de la absorción de la estética de los new romantics, Casal articuló estos elementos, proponiendo un discurso que se percibía como "moderno" y en sintonía con su tiempo. Por ello, resulta legítimo reivindicar a Casal como una de las figuras que, sin estar contemplado, por lo general, dentro del fenómeno de la Movida, articularon de forma más eficaz la modernidad posmoderna que distinguía al período, y que fue importante en la proyección de una imagen de modernización y actualización de España.

\section{BIBLIOGRAFÍA CITADA}

Anónimo. "Casal: Póker para un ganador". El Gran Musical, 233 (Madrid, julio de 1983), p. 33.

-. “Hasta siempre, Tino!”. El Gran Musical, 349 (Madrid, octubre de 1991), pp. 36-37.

. "Tino Casal canta las 40: 'Soy bastante mejor de lo que esperaba"”. El Gran Musical, 315 (Madrid, abril de 1990), pp. 28-20.

."Tino Casal: El último rey del Glam...". Rockdelux, 80 (noviembre de 1991), p. 21.

Arenas, Miguel Ángel. “Tino Casal: La isla del Glamour”. Rock Espezial, 23 (julio de 1983), pp. 46-47.

Arenillas Meléndez, Sara. Discursos, identidades y transgresión en la música popular española (1980-2010): el caso del glam rock y sus variantes. Tesis doctoral, Universidad de Oviedo, 2017.

—_. "El glam en España y su articulación de las identidades de género." Musicología en el siglo XXI: Nuevos retos, Nuevos enfoques, editado por Begoña Lolo y Adela Pre- 
sas. Madrid: Sociedad Española de Musicología, 2018, pp. 2087-2107.

Auslander, Philip. Performing Glam Rock: Gender and Theatricality in Popular Music. Ann Arbor: University of Michigan Press, 2006.

Branch, Andrew. "All the young dudes: educational capital, masculinity and the uses of popular Music." Popular Music, 31/1 (2012), pp. 25-44.

Broackes, Victoria. "Putting out fire with gasoline: desining David Bowie". David Bowie is. Londres:V\&A Publishing, 2013, pp. 116-153.

Buckley, David. Strange Fascination. David Bowie: The Definitive Story. Londres: Virgin Books, 1999.

Cagle, Van M. Reconstructing Pop/Subculture: Art, Rock and Andy Warhol. Thousand Oaks, CA: Sage Publications, 1995.

Cateforis, Theo. Are We Not New Wave? Modern Pop at the Turn of the 1980s. Ann Arbor: University of Michigan Press, 2011.

Domínguez, Salvador. Bienvenido Mr. Rock: los primeros grupos hispanos, 1957-1975. Madrid: Sociedad General de Autores y Editores, 2002.

Erice, Santiago. "Tino Casal. Observándose en el espejo". Popular 1/200 (marzo de 1990), pp. 8-9.

Buckley, David. Strange fascination: David Bowie, the definitive story. Londres: Virgin Books, 1999.

Cateforis, Theo. Are we not new wave?: modern pop at the turn of the 1980s. Ann Arbor: University of Michigan Press, 2011.

Domínguez, Salvador. Bienvenido Mr. Rock: los primeros grupos hispanos, 1957-1975. Madrid: Sociedad General de Autores y Editores, 2002.

Erice, Santiago. "Tino Casal. Observándose en el espejo". Popular, 1/200 (marzo de 1990), pp. 8-9.

Fouce, Héctor. El futuro ya está aquí: música pop y cambio cultural. Madrid: Velecío Editores, 2006.

García Puig, Damián. “Casal. 'Neocasal'. EMI”. Rock Espezial, 5 (enero de 1982), p. 53.

Godes, Patricia. “Casal: Locura o histeria”. Rockdelux, 63 (abril de 1990), p. 35.

González, Lara, ed. Oro Negro: 25 años sin Tino Casal. Madrid y Vizcaya: Grafilur, 2016.

Grossberg, Lawrence. "Rock, posmodernity and authenticity". En We Gotta Get Out of This Place: Popular Conservatism and Postmodern Culture. Londres y Nueva York: Routledge, 1992, pp. 201-39.

Guillén Barrantes, Sergio y Andrés Puente Gómez. "Spain is different". En Glam rock: sexo, purpurina y lápiz de labios. Lleida: Milenio, 2010, pp. 135-145.

Gutiérrez, Juan. Tino Casal. El arte por exceso. Madrid: Ministerio de Educación, Cultura y Deporte, 2017.

Jameson, Fredric. "Postmodernism and Consumer Society." The Anti-Aesthetic: Essays in Postmodern Culture. Port Townsend: Bay Press, 1983, pp. 111-125.
Jaro, C. "Tino Casal: 'He visto la muerte muy de cerca'”. Pronto, 713 (Madrid, 6 de enero de 1986), pp. 6-7.

Jauregui, José Miguel. "Las diez mejores de...Tino Casal". El Gran Musical, 234 (Madrid, agosto de 1983), p. 15.

Johnson, Henry, e Ian Chapman, eds. Global Glam and Popular Music. Style and Spectacle from the 1970s to the 2000s. Nueva York: Routledge, 2016.

Keightley, Keir. "Reconsidering rock". Cambridge Companion to Pop and Rock, editado por Simon Frith, Will Straw y John Street. Cambridge: Cambridge University Press, 2001, pp. 109-42.

Kleinhans, Chuck. "Taking Out the Trash Camp and the Politics of Parody". En The Politics and Poetics of Camp, editado por Moe Meyer. Londres: Routledge, 1994, pp. 182-201.

Kurennaya, Anya. "Look What the Cat Dragged in: Gender, Sexuality, and Authenticity in 1980s Glam Metal". Trabajo de Fin de Master, Master of Arts in Fashion Studies. Nueva York: Parsons School of Design, The New School, 2012.

Laing, Dave. One Chord Wonders: Power and Meaning in Punk Rock. Oakland, CA: PM Press, 1985.

Lechado García, José Manuel. La movida: una crónica de los 80. Madrid: Algaba, 2005.

López Martínez, Andrés. Historias, excesos y tribulaciones de la mal llamada música gay. Lleida: Milenio, 2010.

Manoteras-Maiquez. "Glamoures del underground: All that Kitsch". La Luna de Madrid, 16 (Madrid, marzo de 1985), pp. 38-39.

Manrique, Diego A. "Tino Casal: Peluquería musical”. Rock Espezial, 3 (noviembre de 1981), p. 59.

Metzer, David. "The power ballad". Popular Music, 31/3 (2012), pp. 437-459.

Nichols, William J., y H. Rosi Song. Toward a Cultural Archive of La Movida: Back to the Future. Madison, WI: Fairleigh Dickinson University Press, 2014.

Quintana, Gerardo. Tino Casal: Más allá del embrujo. Madrid: T\&B Editores, 2007.

Quirós, José Antonio. Gran Casal: me como el mundo. Barcelona: Cameo Media, 2004.

Revilla, Federico. Diccionario de iconografía y simbología. Madrid: Cátedra, 2009.

Reynolds, Simon. Retromania: Pop Culture's Addiction to Its Own Past. Londres: Faber and Faber, 2011.

Rimmer, Dave. New Romantics: The Look. Londres: Omnibus Press, 2003.

- Like Punk Never Happened: Culture Club and the New Pop. Londres: Faber and Faber, 2011.

Singla, Joan. "Neo-realismo romántico". Popular 1/102 (Barcelona, diciembre de 1981), pp. 71-72.

Taboada, Carlos. "El hallazgo de Tino Casal". El Gran Musical, 206 (Madrid, abril de 1981), p. 17.

Vallina, Isabel. "El discreto encanto del productor". El Gran Musical, 229 (Madrid, marzo de 1983), pp. 17-19.

Vaquerizo, Mario. Fabiografía: Fabio McNamara. Barcelona: Espasa, 2014. 
Vila, Alberto. "Tino Casal. Tigre Bengalî". El Gran Musical, 240 (Madrid, febrero de 1984), p. 38.

Walser, Robert. Running with the Devil: power, gender, and madness in heavy metal music. Hanover, NH: University Press of New England, 1993.

Warner, Timothy. Pop Music: Technology and Creativity - Trevor Horn and the Digital Revolution. Aldershot: Ashgate, 2003.
Welch, Chris. "Ultravox". Popular, 1/90 (Barcelona, diciembre de 1980), pp. 74-77.

Recibido: 08.10.2018

Aceptado: 06.09.2019 